\title{
SUPER-HOMEM, E A MITOLOGIA MODERNA NOS SUPER-HERÓIS DE HQS
}

Susana de Castro*

RESUMO: O artigo aborda a história do surgimento das revistas em quadrinhos, em particular das revistas de super-heróis. Analisa a origem dos super-heróis na mitologia grega e explica o surgimento do Super-Homem, seus significados, teológicos e culturais. Mostra os temas ético-morais presentes na história do Super-Homem.

Palavras-chave: Super-Homem, Super-Heróis, Deuses olimpianos.

\section{SUPERMAN, AND MODERN MYTHOLOGY IN COMIC BOOK SUPERHEROES}

\begin{abstract}
The article discusses the history of the emergence of comic books, in particular superhero magazines. It analyzes the origin of superheroes in Greek mythology and explains the appearance of Superman, its theological and cultural meanings. It shows the ethical-moral issues present in Superman's history.
\end{abstract}

Keywords: Superman, Superheroes, Olympian Gods

\section{Origem e gêneros}

'Histórias em quadrinhos' ou, simplesmente, 'HQ', é um termo genérico que pode englobar tanto a tira (strip), a caricatura e a charge de jornal, quanto as revistinhas de banca de jornal dedicadas exclusivamente às histórias coloridas escritas em quadros, também chamadas de 'gibis', e os romances ou novelas gráficas (graphic novels), revistas mais caras, autorais, com desenhos mais sofisticados e argumentos mais complexos, voltadas para um público adulto disposto também a pagar mais. O termo graphic novel foi cunhado pelo quadrinista americano Will Eisner quando da publicação de sua obra prima Um contrato de Deus em 1978 (CEZARETTO, 2012, p. 43). As histórias em quadrinhos surgem na primeira metade do século XIX nos jornais e folhetins da Europa (CEZARETTO, 2012, p.6). Das tiras aos gibis, as HQs são marcadas pela sua relação com o meio de reprodução em massa e de informação impressa, o jornal. A tira de humor e a caricatura publicadas diariamente nos jornais expressam mais diretamente a situação social e política do presente. Aqui vale lembrar as maravilhosas tiras do Henfil, como a Graúna ou o Fradim. Em plena ditadura militar brasileira, Henfil fez do desenho e do humor uma forma de crítica política. Mas, os gibis de aventura, fantasia, ficção científica também refletem a realidade histórica na qual estão inseridos. No Brasil, a história dos desenhos em quadrinhos impressos é marcada pelo lançamento

* Professora Associada do departamento de Filosofia da Universidade Federal do Rio de Janeiro. https://orcid.org/00000001-6290-2729 E-mail: decastrosusana@ifcs.ufrj.br 
voltado para o leitor infantil do jornal ilustrado semanal Tico-Tico em 1905. O jornal foi publicado durante mais de 50 anos. Seus personagens, Kaximbown, Zé Macaco, Faustina, Chico Preguiça, Lamparina, Pandareco, Chiquinho e o trio Reco, Bolão e Azeitona, refletiam diversos aspectos da vida nacional (NISKIER, 2006, p.6). Entre os seus desenhistas estava Ângelo Agostini, um dos pioneiros dos quadrinhos no Brasil (CEZARETTO, 2012, p.8).

O universo das histórias em quadrinhos abarca um número grande de gêneros distintos. Há livros históricos como Adeus, chamego Brasileiro, de André Toral, que relata a história da Guerra do Paraguai. Há também versões condensadas de clássicos da literatura, como Casa Grande \& Senzala de Gilberto Freyre, quadrinizado por Estevão Pinto, com desenhos de Ivan Wasth Rodrigues, ou Justine de Guido Crepax, baseado no romance homônimo de Marquês de Sade. Os livros em quadrinhos também abordam a vida de personalidades importantes, como Carolina, escrita por Sirlene Barbosa e desenhada por João Pinheiro, que relata em quadrinhos a vida de Carolina Maria de Jesus. Além desses gêneros, temos também os quadrinhos eróticos, voltados para o público adultos, tais como os livros escritos e desenhados por Milo Manara.

Hoje o universo das histórias em quadrinhos envolve tanto as revistas vendidas em bancas de jornais, quanto edições de luxo, novelas gráficas e livros sobre sua história e significado filosófico vendidos em livrarias. Suas histórias geram filmes, jogos eletrônicos, exposições, seminários, fóruns de discussões, teses e dissertações. Importante, entretanto, salientar que nem sempre foi assim. No começo, intelectuais conservadores, como o psiquiatra alemão radicado nos EUA Fredric Werthan, autor do livro Sedução dos Inocentes (The Seduction of the Innocent, 1954) alegavam que as imagens violentas das HQs teriam um efeito deletério sobre o desenvolvimento das crianças e dos jovens por causa de suas imagens violentas. Mais tarde, durante a guerra fria, período no qual a influência do imperialismo norte-americano se fazia mais forte no subcontinente latino-americano, intelectuais de esquerda como Ariel Dorfman e Armand Mattelart analisaram os aspectos alienantes dos quadrinhos da Walt-Disney em Para Leer al Pato Donald (1971). A situação mudou quando intelectuais e artistas europeus de prestigio passaram a elogiar os quadrinhos como importantes meios de comunicação. Cineastas como Frederico Fellini e Alain Resnais, entre outros, afirmaram não somente que eram leitores de quadrinhos, mas também que estes lhes inspiravam em suas criações cinematográficas; e intelectuais, como o especialista em semiótica Umberto Eco (Apocalipticos a Integrados, 1968) analisaram e estudaram a linguagem dos quadrinhos (CEZARETTO, 2012, p. 34)

Considero as histórias em quadrinhos instrumentos formidáveis, seja fora ou dentro de sala de aula, no processo continuo de aprendizagem e desenvolvimento. Em sala de aula, ao lado de livros didáticos e paradidáticos, filmes e documentários, os quadrinhos servem para ilustrar discussões artísticas e filosóficas sobre temas relevantes do conteúdo pedagógico. Desde a perspectiva exclusivamente formal os quadrinhos também são interessantes no processo cognitivo porque estimulam um tipo de leitura 
diferente da leitura linear, da esquerda para a direita, de cima para baixo, própria aos livros. Na história contada em quadros compostos por desenhos e letras, os leitores olham primeiro para o quadro como um todo, sua imagem, e para as informações contidas nele, e depois começam a interpretar o significado da cena. Dessa forma a HQ possibilita diversas 'entradas' de leitura, exercitando a capacidade de concentração dos leitores de diversas formas. Certamente a HQ não substitui, nem pretende substituir, o livro como meio mais importante de desenvolvimento do raciocínio e da linguagem escrita e falada, mas ela pode ser utilizada pelos professores como mais uma ferramenta de estímulo ao hábito de leitura entre os alunos e também como apoio para discussão em sala de aula sobre tópicos do conteúdo curricular de matérias como artes e filosofia, mas não exclusivamente estas.

\section{As HQs de Super Heróis}

Os quadrinhos de super-heróis surgiram nos Estados Unidos na primeira metade do século passado. A criação dos super-heróis está intimamente ligada a dois fatos históricos: o crash da bolsa de Nova Iorque em 1929, e a consequente recessão econômica mundial, e a Segunda Guerra Mundial. Assim como seus inspiradores, os quadrinhos de detetives, os de heróis, como Batman, também giram em torno das ideias de combater e solucionar crimes. E tal qual as histórias de detetive, os seus desenhos procuram retratar realisticamente o cenário (diferente dos primeiros quadrinhos, cujos cenários eram simples, e havia uma forte presença de animais humanizados, como o Gato Félix). Surgem no período da depressão econômica alimentando a ideia de que um herói poderia proteger as pessoas de bandidos armados e perigosos. Além disso, heróis como Capitão América (da editora Timely alias Marvel Comics) e Super-Homem (da editora Detective Comics alias DC Comics) também combatem o grande inimigo da humanidade, o nazismo. Nessa fase inicial das histórias dos super-heróis há uma clara distinção entre o bem e o mal, e os heróis estão do lado da lei e da ordem, e do Estado.

No que se segue me deterei nas histórias de super-heróis, e depois, em particular, na do SuperHomem a fim de mostrar de que maneira a sua história envolve vários temas filosóficos que podem ser explorados em sala de aula.

\subsection{Super-heróis}

A palavra "herói" vem do grego e significa um guerreiro que além de ter a virtude da coragem, também tem a virtude da responsabilidade pela proteção de sua comunidade. As fontes mais antigas sãos as obras de Homero, Ilíada e Odisseia, que narram a Guerra de Tróia, supostamente ocorrida por volta dos séculos XII e XIII a.C. (ROBB, 2017, p.18). Entre os heróis gregos mais famosos, cujas lendas povoavam o imaginário helênico, figuravam os semideuses Hércules, Aquiles e Teseu, e os humanos, 
Jasão e Ulisses. Diferente dos heróis gregos humanos que se sobressaem pela coragem, audácia e astúcia, os heróis semideuses como Héracles e Perseu, possuem poderes sobre-humanos - na realidade, Perseu, meio-irmão por parte de pai (Zeus) de Héracles, não possui a força sobre-humana do irmão, mas em compensação possui sandálias presenteadas por Hermes que lhe permitem voar.

Na mitologia moderna, os super-heróis das HQs serão desses dois tipos, humanos e semideuses, com poderes extra-humanos. Assim como Ulisses e Jasão, Batman, Homem de Ferro ou Arqueiro Verde são heróis porque aperfeiçoaram seus atributos ou habilidades humanas excepcionais. Outros, como o Super-Homem, já nasceram com capacidades extraordinárias, como capacidade de voar, de escutar a milhares de quilômetros de distância, de conseguir ver por trás de paredes, de disparar raios ultra vermelhos com os olhos, ser mais rápido do que uma bala, derrubar paredes com seu sopro, e, como Héracles, extremamente forte, capaz de levantar coisas imensamente pesadas, como um navio, um avião, ou um trem - como veremos mais adiante, ele possui características não só de um semideus, mas também de um deus (Zeus).

O panteão grego dos doze deuses olimpianos poderia ter formado a primeira equipe de super-heróis. Eles garantiram o seu domínio após derrotarem os Titãs, uma raça mais antiga de deuses superpoderosos. Muitos dos seus poderes, tais como, capacidade de dominar o fogo, de voar, de dominar os mares e a natureza, foram replicados na mitologia moderna dos super-heróis das histórias em quadrinhos.

Hoje, os filmes de super-heróis batem recordes de bilheteira ${ }^{1}$, mas não teriam sido possíveis sem as histórias em quadrinhos. Normalmente se divide a história da HQs de super-heróis em quatro 'eras'. A primeira, a Era de Ouro, começa em 1938 -- nove anos após a queda da bolsa de valores de Nova Iorque que provocou uma depressão econômica mundial, e no ano no qual Hitler declara-se ditador da Alemanha, após vencer as eleições cinco anos antes --, com o lançamento de Super-Homem pela National Comics (que depois viraria a Detetiv Comics, alias DC), e termina em meados dos anos 1950, quando começa uma campanha contra as revistas por seu conteúdo 'violento' e já não havia mais a guerra e o inimigo nazista para alimentar a imaginação dos quadrinistas e leitores. A segunda, a Era de Prata, vai da metade da década de 1950 e vai até 1970, e é marcada pela contracultura da década de 1960. Deu origem a muitos novos super-heróis, como os X-Men e o Homem-Aranha da Marvel Comics. A Era de Prata é a 'Era da Marvel' (HOWE, 2012). Além dos X-Men e do Homem-Aranha, a Marvel lança Hulk e o Homem de Ferro. A noção de que os super-heróis sabem distinguir perfeitamente o bem do mal, e que são obedientes protetores da lei e da ordem é substituída pela ideia de que tal qual qualquer ser-humano os heróis sofrem de insegurança, angústia, medo, e não possuem uma relação tranquila com os representantes da lei e da ordem (CEZARETTO, 2012, p. 21). A terceira, a Era de Bronze, dura da década de 1970 até metade da década de 1980. Foi uma época, para alguns, de declínio e estagnação dos super-heróis (ROBB, 2017, p.

\footnotetext{
${ }^{1}$ Em 2012 o filme Os Vingadores, baseado em uma equipe de super-heróis criada na década de 1960 pela Marvel Comics arrecadou 1,5 bilhão de dólares, o que representou a terceira maior bilheteria de todos os tempos (Robb, 2017, p. 13).
} 
15), para outros, uma época em que há um apelo muito forte ao multiculturalismo, diferenças raciais e étnicas (como os quadrinhos do X-Men, por exemplo), e também de dúvida acerca da infalibilidade do Estado e desconfiança de que este está a serviço de interesses escusos (CEZARETTTO, 2012, p.21). A quarta Era, a de Ferro (também chamada Moderna, ou de Cobre), vai da metade da década de 1980 até os dias de hoje. Nessa última, os conflitos internos dos super-heróis passam a ter papel fundamental dentro da narrativa. Os heróis se tornaram mais sombrios. O início dessa última era foi o lançamento da graphic novel Watchmen do britânico Alan Moore.

Publicada originalmente em doze edições entre 1986 e 1987 pela DC Comics. Watchmen foi responsável pela mudança de tom em muitas histórias em quadrinho. Em um mundo onde os vigilantes e mascarados são ilegais (devido à Lei Keene), e não possuem superpoderes, com exceção do Dr. Manhattan, Watchmen mostra uma realidade cruel, em uma Nova York ambientada em meados dos anos 80. Na história, o presidente dos Estados Unidos, Richard Nixon, foi eleito para um longínquo governo. Uma história na qual o escândalo de Watergate (ocorrido e investigado entre 1972 e 1974), responsável por sua renúncia no mundo real, nunca chegou a acontecer. Na época em que foi lançado, os Estados Unidos viviam o segundo mandato de Ronald Reagan, conhecido pelo conservadorismo e adesão aos princípios neoliberais. Nesse momento social e político conservador, não havia clima para escrever sobre heróis nacionais capazes de enormes sacríficos em nome do bem comum.

\section{$2.2 \quad$ Super-Homem, a origem}

O Super-Homem surgiu na edição de junho de 1938 da Action Comics. Vendida a 10 cents na época, foi a primeira revista em quadrinhos a ser comprada por 1milhão de dólares em um leilão, em 2010 (ROBB, 2017, p.12). Jerry Siegel e Joseph Shuster, roteirista e desenhista do Super-Homem, venderam os direitos autorias de sua criação por 130 dólares. Tinham na época 23 anos, e haviam passado 7 anos buscando construir o personagem (MORRISON, 2012, p.30; VOLOJ \& CAMPI). Não podiam imaginar o estrondoso sucesso do personagem, que faria do Super-Homem um produto altamente rentável: "vendia selos, cartões de felicitações, livrinhos de colorir, chicletes, jogos de tabuleiro" (MORRISON, 2012, p.28). O que foi que ocorreu de excepcional com esse personagem que fez com que ele se tornasse um verdadeiro ícone?

Há alguns elementos que são realmente inovadores. A letra S no peito. "Estampar agressivamente a inicial no peito era algo que nunca havia sido feito, e foi um golpe de mestre em marketing. Superman usava seu próprio logotipo. Ele era sua própria camiseta.” (MORRISON, 2012, p. 32). Havia também o desenho inovador de Joe Shuster. As ações eram tantas que o leitor ficava sem fôlego: ao fim de treze páginas da sua estreia, Super-Homem havia prendido cinco infratores e ainda havia extirpado a corrupção no Senado dos Estados Unidos. (MORRISON, 2012, p. 27). Nas primeiras histórias, ele não voava, apenas dava saltos. Seus poderes foram aumentando ao longo dos anos, por isso Grant Morrison afirma 
que ele foi deixando de ser semideus para ser um deus. A história da sua chegada ao planeta terra, remete à história bíblica de Jesus Cristo. O S.-H. 'cai do céu' ainda bebê e é adotado por um casal sem filhos. Depois se descobre que ele não era um ser ordinário, mas sim filho de um ser de outra galáxia, Jor-El.

\subsection{Questões éticas e morais}

As histórias em quadrinhos sobre super-heróis podem servir de apoio para pensar questões éticas e morais na aula de filosofia, uma vez que, como mostrarei em seguida, partem de uma inspiração teológica bem importante, "se Deus existe então porque ele não intervém diretamente para evitar a dor, o sofrimento e a morte dos seres humanos? ”. Nos recordemos que o filósofo alemão Friedrich Nietzsche foi o primeiro a anunciar tanto a 'morte de deus', isto é, a morte da crença na existência de um ser divino que governasse as vidas humanas, quanto o surgimento de um super-humano (Übermensch). Certamente Nietzsche não pensou o super-humano como alguém com capacidades físicas sobre-humanas. No seu caso 'super' (Über-), de super-homem, representa a superação do niilismo, mas no caso dos criadores do primeiro herói moderno das histórias em quadrinhos, os jovens amigos moradores de Cleveland, Jerry Siegel, roterista, e Joe Shuster, desenhista, o Super-Homem era um herói vindo dos céus para salvar a humanidade: evitar catástrofes atômicas, descarrilamentos de trens, quedas de aviões, assassinatos, roubos etc. Em plena recessão econômica, ocasionada pela quebra da bola de valores de Wall Street em 1929, observando a dificuldade financeira dos seus pais, judeus imigrantes, os dois jovens imaginaram que estava na hora de reviver a mitologia grega adaptando-a aos tempos modernos, industriais, e também associando-a a uma outra 'mitologia', a judaico-cristã. Diferente do super-homem nietzschiano que desprezava os valores cristãos de compaixão e misericórdia, o Super-Homem de Jerry e Joe foi construído como um salvador cristão que se comove com a dor do outro e abre mão da sua felicidade para ajudar quem quer que precisasse da sua ajuda (BARKMANN, 2014, p. 126)

Diferente dos deuses e deusas gregas, o Super-Homem, super-herói com a força de Hércules e a rapidez de Hermes, não era moralmente ambíguo. Seu papel era o de proteger vidas humanas em todas circunstâncias, combater o crime e as injustiças. De maneira geral, os super-heróis da chamada Era de Ouro das HQs exibem uma dedicação altruísta ao bem público, ou seja, lutam pela justiça sem expectativa de nenhum reconhecimento ou ganho pessoal, sacrificando, inclusive, muitas vezes suas vidas pessoais. O que há em comum aos deuses da antiguidade e os super-heróis da modernidade é que todos interferem concretamente na vida dos seres humanos. Os jovens Jerry e Joe sabiam, entretanto, que o público leitor do século XX não apreciaria histórias místicas ou religiosas, por isso o Super-Homem vem do céu, mas não porque é uma divindade, mas sim porque é um habitante de outro planeta, Kripton. Essa solução foi completamente acertada. Super-Homem caiu no gosto dos jovens e vendeu um milhão de exemplares na sua primeira edição. Ao propor na figura do Super-Homem uma intervenção 'celeste' para as desgraças terrenas, de tal modo que pelo menos os jovens e as crianças pudessem ter esperança que alguém, algum 
ser heroico com poderes sobre humanos, iria impedir os desastres e evitar a dor e a morte dos habitantes da terra, em particular, da cidade fictícia "Metrópolis" - uma homenagem dos autores ao filme homônimo de Fritz Lang, lançado em 1927-, Joe e Jerry foram verdadeiros intérpretes dos anseios da sua época.

Do ponto de vista filosófico, é interessante imaginar quais são as razões pelas quais o Super-Homem age altruisticamente, colocando-se sempre disponível para ajudar onde quer que haja alguém em risco de vida. Ele não poderia igualmente aproveitar seus superpoderes para dominar a terra? O que o faz ser alguém virtuoso, comprometido com a ação justa e correta? Se sua nave espacial, ao invés de ter caído na fazenda do casal de fazendeiros americanos Jonathan e Martha Kent, em meados da década de 1920 do século passado, tivesse caído na fazendo de um casal da Baviera, na Alemanha, o que teria acontecido? Se Hitler soubesse da sua existência não há a menor dúvida que ele iria fazer dele uma máquina de guerra, acarretando o domínio do mundo pelo nazismo. Mas nesse caso, se ele fosse doutrinado a achar que conquistar o mundo era uma atividade desejável, o que o faria não querer dominar ele mesmo o mundo? (SHARP, 2014) Como estamos em outra época, não mais premida entre a depressão econômica e a Segunda Guerra Mundial, a moralidade de um homem que detém mais força do que qualquer ser humano pode ser questionada.

No romance gráfico The Boys, roteirizado por Garth Ennis e desenhado por Tony Aviña ${ }^{2}$, o SuperHomem é parodiado através do personagem Homeland. Este sabe que sua força o torna imbatível e, por isso, finge ser um bom mocinho para o público que assiste às suas façanhas pela televisão, mas, na verdade, é um assassino cruel e impiedoso, que elimina todos os que se interpõem em seu caminho de domínio do mundo.

Em 1933, enquanto o mundo já havia tomado conhecimento de Hitler e seu discurso antissemita, Joe Shuster e Jerry Siegel escreveram um conto de ficção científica distópico publicado na Science Fiction número 3, chamado “O Reino do Super-Homem”. Nele um indivíduo comum é cobaia de um experimento e ganha superpoderes. Embriagado por seu poder, ele usa sua força para o mal e aspira governar o mundo (VOLOJ \& CAMPI, 2018, p. 45; BARKMAN, 2014, p. 127). Nessa época já se

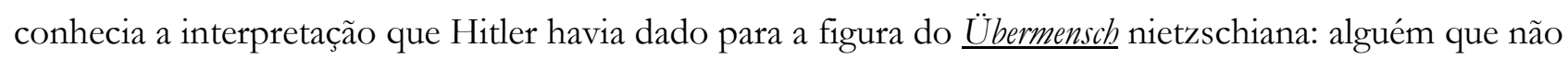
sentiria misericórdia, piedade ou empatia pelos seus semelhantes, e que não mediria esforços para conquistar seus objetivos (BARKMAN, 2014, p. 127). Além disso, alguém que não pautaria suas ações pela moral comum, mas sim pelo objetivo de acumulo de poder. Joe e Jerry estavam pensando na figura hitleriana do Super-Homem quando escreveram o conto - que marca o início dos sete anos que levaram 'construindo' o Super-Homem. Portanto, antes de ser o salvador e protetor dos seres humanos, SuperHomem foi um criminoso. É importante salientar que não há relação entre a interpretação hitleriana do

\footnotetext{
${ }^{2}$ A plataforma streaming Amazon Prime produziu uma série baseada nesse HQ. Cuja segunda temporada estreou em setembro de 2020 .
} 
super-homem de Nietzsche e o que este pensava sobre o significado do super-homem. Para Nietzsche, diante da morte de Deus a visão de uma moralidade objetiva que justificasse as ações humanas vai por água a baixo. O ser humano está, então, livre, acreditava Nietzsche, para buscar construir os valores com os quais pautar a sua vida, sem se preocupar com o que os outros pensassem ou dissessem sobre isso. $\mathrm{O}$ primeiro compromisso do super-homem nietzschiano é consigo mesmo, com seu projeto de construção de vida criativamente, indiferente aos olhares e julgamento dos seus semelhantes. Diferente do que pensava Hitler, para Nietzsche, não passa pela cabeça de um sujeito preocupado com seu projeto de vida, que a conquista do mundo seja um bem desejado.

Ao contrário do super-homem nietzschiano, marcado pela vontade de superação do niilismo diante da morte de Deus e da ausência de moral objetiva e universal, a segunda versão do super-homem, a dos amigos Jerry e Joe, é a de um ser alienígena comprometido com os princípios morais judaico-cristãos. Eles, de certa forma, inverteram o primeiro sentido, megalomaníaco que haviam retirado da interpretação hitleriana do super-homem de Nietzsche.

O fato de o Super-Homem vir do espaço, de outro planeta, poderia fazer com que pudéssemos supor que seu altruísmo fosse de fachada, e que, na verdade, seu objetivo é conquistar a terra ${ }^{3}$. No então, isso nunca apareceu ao longo das décadas e mais décadas de histórias do Super-Homem. O público não questiona o jeito $100 \%$ correto do Super-Homem, apesar da sua origem alienígena. Não podemos esquecer que, apesar da sua origem extraterrestre, ele foi criado por dois fazendeiros que seguiam um código de ética cristão muito forte. Um dos princípios mais fortes da moral do Super-Homem é o "não matarás" dos dez mandamentos da moralidade cristã. Quando isso por alguma razão ocorre, ele sofre de remorsos e dor de consciência (BARKMAN, 2014, p.130-131). Por outro lado, é importante salientar que o Super-Homem passa pelos processos de julgamento moral ao qual todos passamos ao longo das nossas vidas, o que faz com que o leitor pense nele muito mais como um humano do que como um extraterrestre.

Na conquista do objetivo de fazer o bem ao maior número de pessoas, o Super-Homem algumas vezes é obrigado a refletir, como qualquer reles mortal, sobre qual curso de ação deve escolher. Quando está em jogo a vida de diferentes pessoas em diversas partes do planeta, ele tem que refletir a quem irá socorrer primeiro. Como qualquer ser humano, ele também se defronta com dilemas morais, nos quais precisa elaborar um julgamento prático a fim de decidir sobre o curso da sua ação, pois por mais que seja o Super-Homem e possa estar em vários lugares distantes um do outro em curto espaço de tempo, existe um limite para a sua ação simultânea. Algumas vezes ele será obrigado a amargar a impossibilidade de atender a todos que necessitem de ajuda (FELTHAM, 2014).

\footnotetext{
${ }^{3}$ Esse é inclusive o argumento do filme Brightburn (2019), dirigido por David Yarovesky.
} 
Outro tipo de dilema moral, diz respeito ao seu relacionamento amoroso. Considerando que os indivíduos nas grandes metrópoles urbanas estão sempre expostos ao perigo, o Super-Homem vive salvando pessoas e acaba tendo pouco tempo para si. Mas seu romance com Louis Lane é uma parte importante da sua vida e ele cuida para que esse relacionamento não se acabe apesar da sua impossibilidade de se dedicar a ele o tanto que gostaria. Então, para fins de cuidado com sua vida íntima, ele não abre mão de momentos de intimidade com sua amada, mesmo que isso signifique a sua indisponibilidade para salvar vidas. Não fosse seus laços de amizade e amor por Louis Lane, talvez muitos dos dilemas pelos quais ele passa ao longo de sua história não teriam ocorrido. Mas o fato é que em sua missão de salvar o mundo, muitas vezes ele é obrigado a ter que decidir a quem deve salvar primeiro, a sua namorada, ou, por exemplo um ônibus escolar cheio de criança. Do ponto de vista da ética utilitarista, seu processo de julgamento e tomada de decisão deve levar em consideração as consequências do seu ato, caso se decida por uma ou outra ação. Já um modelo de raciocínio deontológico levaria em consideração a intenção e a motivação, que deve ser válida universalmente independe das circunstâncias particulares. Se ele, entretanto, se guiasse no seu julgamento pela linha de raciocino da ética aristotélica da virtude, ele se perguntaria o que seu pai faria em uma situação dessas. Mesmo a moral kantiana deontológica, reconhece que o julgamento deve ser analisado caso a caso. Agir por princípio não pode significar pôr sempre de lado todas as circunstancias particulares (White, 2014).

\section{Conclusão:}

Para viver na terra, o 'deus' extraterrestre Super-Homem foi obrigado a fazer alguns sacrifícios, tais como, criar um disfarce para poder caminhar entre os seres-humanos comuns sem ser reconhecido. Quando nasceu nas mãos dos jovens amigos Jerry e Joe, ele era visto como um salvador dos oprimidos e indefesos contra as ações dos políticos corruptos e dos gângsteres, mas com o passar do tempo, o personagem foi se tornando em mais um produto rentável da indústria de entretenimento. Todo seu apelo ‘divino’ e 'heroico’ perdeu sua aura mágica. 


\section{REFERÊNCIAS}

BARKMAN, Adam. "Super-Homem; de Anticristo a Arquétipo de Cristo". In: White, Mark (org.) Superman e a filosofia. Trad. João Barata. São Paulo: Madras, 2014.

CEZARETTO, André Luís Sanchez. De quadro a quadro - introdução à história das HQs. Brasília: Caixa Cultural, 2012.

FELTHAM, Brian. "Histórias em Quadrinhos! O Super-Homem e a Razão prática”. In: White, Mark (org.) Superman e a filosofia. Trad. João Barata. São Paulo: Madras, 2014.

HOWE, Sean. Marvel Comics- a história secreta. Trad. Érico Assis. São Paulo: LeYa, 2013.

MORRISON, Grant. Superdeuses - Mutantes, Alienigenas, Vigilantes, Justiceiros, Mascarados e o significado de ser bumano na era dos super-heróis. Trad. Érico Assis. São Paulo: Seoman, 2012.

NISKIER, Arnaldo. “O Tico-Tico” Prefácio. In: Instituto Antares (org.). Almanaque o Tico-Tico. Rio de Janeiro: Edições Consultor, 2006.

ROBB, Brian j. A identidade secreta dos super-heróis. Trad. André Gordirro. Rio de Janeiro: Valentina, 2017.

SHARP, Robert. "Poderia o Super-Homem Ter se Juntado ao Terceiro Reich? A Importância e as Falhas da Educação Moral”. In: White, Mark (org.) Superman e a filosofia. Trad. João Barata. São Paulo: Madras, 2014.

VOLOJ, Julian; Campi, Thomas. Joe Shuster - una historia a la sombra de Superman. Trad. Fernando Ballesteros. Madri: DIBBUKS, 2018.

WHITE, Mark D. “Julgamento Moral; o Poder que Faz do Super-Homem um Humano”. In: White, Mark (org.) Superman e a filosofia. Trad. João Barata. São Paulo: Madras, 2014. 